\title{
Dynamic Balance Measures in Healthy and Chronic Ankle Instability Participants While Wearing Ankle Braces: Systematic Review With Meta-Analysis
}

\author{
Robert J. Reyburn and Cameron J. Powden
}

\begin{abstract}
Context: Ankle braces have been theorized to augment dynamic balance. Objectives: To complete a systematic review with metaanalysis of the available literature assessing the effect of ankle braces on dynamic balance in individuals with and without chronic ankle instability (CAI). Evidence Acquisition: Electronic databases (PubMed, MEDLINE, CINAHL, and SPORTDiscus) were searched from inception to October 2019 using combinations of keywords related to dynamic balance, ankle braces, Star Excursion Balance Test (SEBT), Y-Balance Test (YBT), and Time to Stabilization. Inclusion criteria required that studies examined the effects of ankle braces on dynamic balance. Studies were excluded if they evaluated other conditions besides CAI, did not access dynamic balance, or did not use an ankle brace. Methodological quality was assessed using the Physiotherapy Evidence Database scale. The level of evidence was assessed using the Strength of Recommendation Taxonomy. The magnitude of brace effects on dynamic balance was examined using Hedges $g$ effect sizes (ESs) and 95\% confidence intervals (CIs). Random-effects meta-analysis was performed to synthesize SEBT/YBT and Time to Stabilization data separately. Data Synthesis: Seven studies were included with a median Physiotherapy Evidence Database score of 60\% (range 50\%-60\%), and 4 were classified as high quality. Overall meta-analysis indicated a weak to no effect of braces on SEBT/YBT (ES $=0.117 ; 95 \% \mathrm{CI}$, -0.080 to $0.433 ; P=.177$ ) and Time to Stabilization ( $\mathrm{ES}=-0.064 ; 95 \% \mathrm{CI},-0.211$ to $0.083, P=.083$ ). Subanalysis of SEBT/ YBT measures indicated a weak negative effect in healthy participants ( $\mathrm{ES}=-0.116 ; 95 \% \mathrm{CI},-0.209$ to $-0.022, P=.015)$ and a strong positive effect in individuals with CAI $(\mathrm{ES}=0.777 ; 95 \% \mathrm{CI}, 0.418$ to $1.136 ; P<.001)$. Conclusion: The current literature supports a strong effect of ankle braces on the SEBT/YBT in those with CAI. However, little to no dynamic balance changes were noted in healthy participants. Future research should include consistent ankle brace types, pathologic populations, and the examination of dynamic balance changes contribution to injury risk reduction.
\end{abstract}

Keywords: postural control, Star Excursion Balance Test, time to stabilization, Y-balance test

Ankle sprains are often viewed by athletic populations as minor injuries with limited impacts. However, acute ankle sprains result in immediate effects such as pain, swelling, weakness, giving way, and time missed from work/activity. ${ }^{1}$ Individuals who suffer an ankle sprain report a continuation of symptoms 2 years after injury. ${ }^{1}$ Furthermore, $40 \%$ to $70 \%$ of individuals who suffer an acute ankle sprain will go on to develop a condition such as chronic ankle instability (CAI). ${ }^{2,3}$ The CAI is characterized by repetitive episodes of "giving way," diminished functional ability and recurrent sprains. ${ }^{3}$ The repetitive trauma associated with CAI leads to long-term impairment of the ankle joint and health-related quality of life deficits. ${ }^{2}$ Specifically, those with CAI report self-perceived functional deficits and increased fear of reinjury, ${ }^{4}$ which may contribute to the reports of decreased physical activity levels within the population. ${ }^{5}$ These long-term consequences place those with $\mathrm{CAI}$ at an increased risk of developing posttraumatic osteoarthritis. ${ }^{6}$ This health concern is further exacerbated by the high incidence rate of acute ankle sprains, 7.2 sprains per 1000 person hours, in the United States. This equates to hundreds of thousands of ankle sprains each year. ${ }^{7}$ Overall, the abundancy of acute and recurrent ankle

Reyburn is with the Doctorate in Athletic Training Program, Indiana State University, Terre Haute, IN, USA. Powden is with the Masters of Science in Athletic Training Program, University of Indianapolis, Indianapolis, IN, USA. Powden (powdenc@uindy.edu) is corresponding author. sprains in combination with their short- and long-term impacts demonstrates the importance of preventative measures.

Prophylactic ankle bracing is a potential prevention strategy to reduce the incidence of ankle sprains. Within the literature, ankle bracing has reduced the rate of ankle sprains within high school athletes. ${ }^{8-10}$ Specifically, their use resulted in a reduction in injury rate from 1.12 to 0.48 injuries per 1000 exposures. ${ }^{10}$ While, ankle bracing has proven effective, there is a lack of evidence for the mechanism of effect. ${ }^{11}$ The proposed prophylactic mechanisms of ankle braces are thought to be due to mechanical range of motion reductions, effects on balance, and proprioceptive changes. ${ }^{12}$ Mechanically, ankle braces have proven their ability to restrict range of motion, and this has been proposed to reduce the chance of inversion injury moments. ${ }^{13}$ Proprioceptive effects of ankle braces are thought to be due to the stimulation of cutaneous sensors to provide enhanced sensory feedback at the ankle and allow for greater awareness of the ankle in space and time. ${ }^{13}$ Finally, dynamic balance is the body's ability to maintain a stable upright posture during movement. ${ }^{14,15}$ Ankle braces may affect dynamic balance through a collection of mechanical and sensory effects. ${ }^{14,15}$ Furthermore, dynamic balance has been cited as a predictor of lower-extremity injuries. ${ }^{16}$ Exploring the effect that ankle braces have on dynamic balance is useful due to the connection with injury risk.

There are currently several studies that assess dynamic balance under different stabilization conditions. ${ }^{15,17-22}$ These studies include a variety of ankle stabilizing techniques, such as taping and bracing 
during different functional tasks such as walking or running. Dynamic balance has been examined in participants wearing ankle braces using the Star Excursion Balance Test/Y-balance Test (SEBT/YBT) and Time to Stabilization (TTS) measures. However, there has been no comprehensive study that has examined the overall effect of ankle braces on dynamic balance to aid in clinical decision making. Synthesizing the available literature will help to provide evidence on best practices regarding the use of ankle braces in active individuals.

\section{Objectives}

The purpose of this systematic review is to collect, critically appraise, and synthesize the available literature on how ankle braces influence dynamic balance measures in healthy participants and those with CAI.

\section{Evidence Acquisition}

\section{Search Strategy}

A systematic search of the literature was conducted using the Preferred Reporting Items for Systematic Reviews and MetaAnalysis guidelines ${ }^{23}$ to find articles evaluating the effect of ankle braces on dynamic balance. Electronic databases PubMed and EBSCO Host (CINHAL, MEDLINE, and SPORTDiscus) were searched from inception through October 2019. These were searched using combinations of keywords related to the SEBT, YBT, TTS, dynamic balance, and ankle braces (Table 1). Boolean operators "OR" and "AND" were employed to combine search terms. The Boolean phrase and systematic search were derived and completed by investigators (C.J.P. and R.J.R.).

\section{Eligibility Criteria}

Investigators (C.J.P. and R.J.R.) reviewed identified studies against eligibility criteria. Initially, potential eligibility was determined by titles and abstracts. In cases in which eligibility was uncertain, the full text of the manuscript was reviewed for inclusion. Eligibility criteria are provided below.

\section{Inclusion Criteria}

The following inclusion criteria were used to screen studies:
1. Study purpose: studies were included if the primary aim was to evaluate the effects of ankle braces on dynamic balance (ie, TTS, SEBT, YBT, etc).

2. Type of participants: studies on adult ( $\geq 18$ y of age) human participants who were classified as either being free of injury (healthy) or with having CAI were included.

3. Type of outcome measures: studies that assessed dynamic balance and postural control using measures such as TTS, SEBT, and/or YBT were included.

\section{Exclusion Criteria}

The following exclusion criteria were used to screen studies:

1. Studies that didn't assess dynamic balance or postural control were excluded.

2. Studies which included participants who were under the age of 18 years were excluded.

3. Studies that included participants with preexisting conditions other than CAI were excluded.

4. Studies not published in English were excluded.

\section{Assessing Quality of Studies}

The methodological quality of the included studies was assessed using the Physiotherapy Evidence Database (PEDro) scale. The PEDro is designed to measure methodological quality of clinical trials. ${ }^{24}$ The PEDro is scored using 1 if present and 0 if not present with a total score of 0 to $10 .^{24}$ Included studies were considered to be of high quality if they met $60 \%$ of the criteria or higher. Initially, 2 reviewers (C.J.P. and R.J.R.) scored the selected studies independently. Reviewers then met to develop a consensus for each study. Any disagreements that could not be brought to consensus through discussions were resolved using an independent reviewer.

\section{Data Extraction}

Two reviewers (C.J.P. and R.J.R.) extracted data during the primary review. The extracted data included the following: study design, aims, population, type of ankle brace used, and outcome measures. Discussion and an independent reviewer were used to resolve any discrepancies in interpretation if needed.

After extraction, data were further categorized based on outcome measure. The primary outcomes for this review were the SEBT/YBT and TTS. Means, SDs, and number of participants

Table 1 Search Strategy, Keywords, and Search Terms Used

\begin{tabular}{|c|c|c|c|c|}
\hline Step & Search terms & Boolean operator & EBSCO Host & PubMed \\
\hline 1 & Ankle & & 114,192 & 70,681 \\
\hline 2 & $\begin{array}{c}\text { Brace } \\
\text { Orthosis }\end{array}$ & OR & 31,784 & 18,495 \\
\hline 3 & $\begin{array}{c}\text { Dynamic balance } \\
\text { Y-Balance Test } \\
\text { Star Excursion Balance Test } \\
\text { Time to Stabilization }\end{array}$ & OR & 9591 & 29,115 \\
\hline 4 & 1,2 & AND & 5836 & 3006 \\
\hline 5 & $1,2,3$ & AND & 56 & 97 \\
\hline Duplicates & & & & $35^{\mathrm{a}}$ \\
\hline Total identified & & & & 118 \\
\hline
\end{tabular}

${ }^{\mathrm{a}}$ Total number of duplicates between EBSCO and PubMed. 
were extracted for both outcome measures. During extraction, scores for each reach direction of the SEBT/YBT were extracted separately. To further categorize the data, the moderator variable of participant group was created to separate point estimates into either healthy or CAI participants.

\section{Data Analysis and Synthesis}

Separate summary meta-analyses were performed for each outcome variable (SEBT/YBT and TTS). A total of 2 summary metaanalyses were completed. For summary analyses, multiple point estimates from the same study were pooled to reduce sample size inflation. A subanalysis was conducted to examine ankle brace's effects on the SEBT/YBT in healthy and CAI participant groups separately. Similar subanalysis was not completed for TTS due to a lack of participant groups.

Each meta-analysis was completed by using either randomeffects or fixed-effects models, in which individual point estimates were pooled from the included studies using bias-corrected Hedges $g$ effect sizes (ESs) and 95\% confidence intervals (CIs) to determine the magnitude of effect. Given substantial levels of heterogeneity within SEBT/YBT measures $\left(I^{2}=87.91 \%, Q\right.$ value $=$ 82.71, $P<.001)$ and CAI-specific SEBT/YBT measures $\left(I^{2}=\right.$ $74.14 \%, Q$ value $=11.60, P=.009)$ random-effects models were used. No heterogeneity was observed in the TTS measures $\left(I^{2}=\right.$ $0.00 \%, Q$ value $=2.85, P=.581)$ and healthy specific SEBT/YBT measures $\left(I^{2}=0.00 \%, Q\right.$ value $\left.=2.53, P \leq .865\right)$; thus, a fixedeffect model was used. Positive ESs indicated greater levels of dynamic balance in the brace group compared with nonbraced. All meta-analysis procedures were completed in Comprehensive MetaAnalysis (version 3.3.070; Biostat Inc, Englewood, NJ). We interpreted ESs as weak $(\leq 0.40)$, moderate $(0.41-0.69)$, or strong $(\geq 0.70)$. The alpha level was set a priori at .05 . To further examine the data, we performed a qualitative assessment of ESs and CIs by assessing the differences in ES estimates between groups and determining whether the CIs crossed 0 .

\section{Sensitivity Analysis}

A 1-study-removed analysis was completed to examine the influence of a single-participant group on the observed summary effect of each summary analysis. This method explores the effect of removing single-participant groups on the observed summary effect. In addition, the effect of quality criteria on the assumptions of level of evidence for high-quality studies $(\geq 60 \%)$ was tested by subjecting the criteria to changes of $\pm 10 \%$ and determining the subsequent level of evidence change.

\section{Level of Evidence and Grade of Recommendation}

The Strength of Recommendation Taxonomy (SORT) was used to categorize the data. Quality, quantity, and consistency of the assessed body of literature allows a grade of recommendation based on the evidence. ${ }^{25}$ Individual studies were categorized as level 1 , level 2 , and level 3 evidence. ${ }^{25}$ That evidence was used to determine the strength of recommendations. A-level recommendations are based on good quality patient-oriented evidence. B-Level recommendations are based on limited quality patient-oriented evidence. C-Level recommendations are based on consensus, usual practice, opinion, and disease-oriented evidence. ${ }^{25}$

\section{Evidence Synthesis}

\section{Literature Search}

A total of 118 studies were retrieved from electronic and hand searches. Figure 1 displays a diagram outlining the results of the search and study review process. Of those, 7 studies were identified as meeting the selection criteria. Six studies were identified through electronic search. ${ }^{15,17,18,20-22}$ One study was identified through hand search. ${ }^{17}$

\section{General Characteristics}

The study characteristics of included studies are displayed in Table 2. All studies included had examined dynamic balance with and without ankle braces in individuals with and/or without CAI. One study included soft, ${ }^{17} 5$ studies included semiriged, ${ }^{15,17,19,20,22} 5$ studies included lace-up ankle braces, ${ }^{15,18,20-22}$ and one study included combined mechanism ankle support. ${ }^{19}$ Four studies included participants with CAI, ${ }^{17,19-21}$ while 5 included healthy participants. ${ }^{15,17-19,22}$ Four studies examined dynamic balance using the SEBT/YBT. ${ }^{15,17-19}$ Three studies examined dynamic balance using TTS. ${ }^{20-22}$

\section{Methodological Quality}

The 2 reviewers (C.J.P. and R.J.R.) agreed on 69/70 (99\%) items on the PEDro checklist. The one difference in PEDro score was resolved by discussion between the reviewers. Seven level 2 studies with quality scores that ranged from $50 \%$ to $60 \%$ with a median PEDro score of $60 \%$ were included in the summary data (Table 3). Four studies assessing dynamic balance with SEBT/ YBT had PEDro scores of $60 \%$ were included in summary data. ${ }^{15,17-20}$ Three studies assessing dynamic balance with TTS ranged from $50 \%$ to $60 \%$ with a median PEDro score of $50 \%$ were also included in this study. ${ }^{20-22}$

\section{Data Synthesis}

All individual ES and summary effects are presented in Figures 2 and 3 .

Summary Analyses. For the SEBT/YBT, there was an overall weak summary effect for ankle braces improving SEBT/YBT measures $(\mathrm{ES}=0.177 ; 95 \% \mathrm{CI},-0.080$ to 0.433$)$ that was not significant $(P=.177)$. For TTS, there was a null summary effect for ankle braces influencing TTS measures $(\mathrm{ES}=-0.064 ; 95 \% \mathrm{CI}$, -0.211 to 0.083$)$ that was not significant $(P=.392)$.

Participant Group. The results of the subanalysis of participant group for increasing SEBT/YBT measures indicated that there was a weak negative effect in healthy participants $(E S=-0.116 ; 95 \%$ CI, -0.209 to $-0.022 ; P=.015)$ and a strong positive effect in individuals with $\mathrm{CAI}(\mathrm{ES}=0.777 ; 95 \% \mathrm{CI}, 0.418$ to 1.136 ; $P<.001)$. It is important to note that results of the CAI analysis were derived from 2 studies ${ }^{17,19}$ completed by one research group 5 years apart. In addition, a total of 4 unique ankle braces were used in these studies with no 1 brace being used in both studies.

\section{Sensitivity Analysis}

The 1-study-removed analysis for SEBT/YBT demonstrated that the overall ES remained weak and ranged from 0.100 to 0.227 


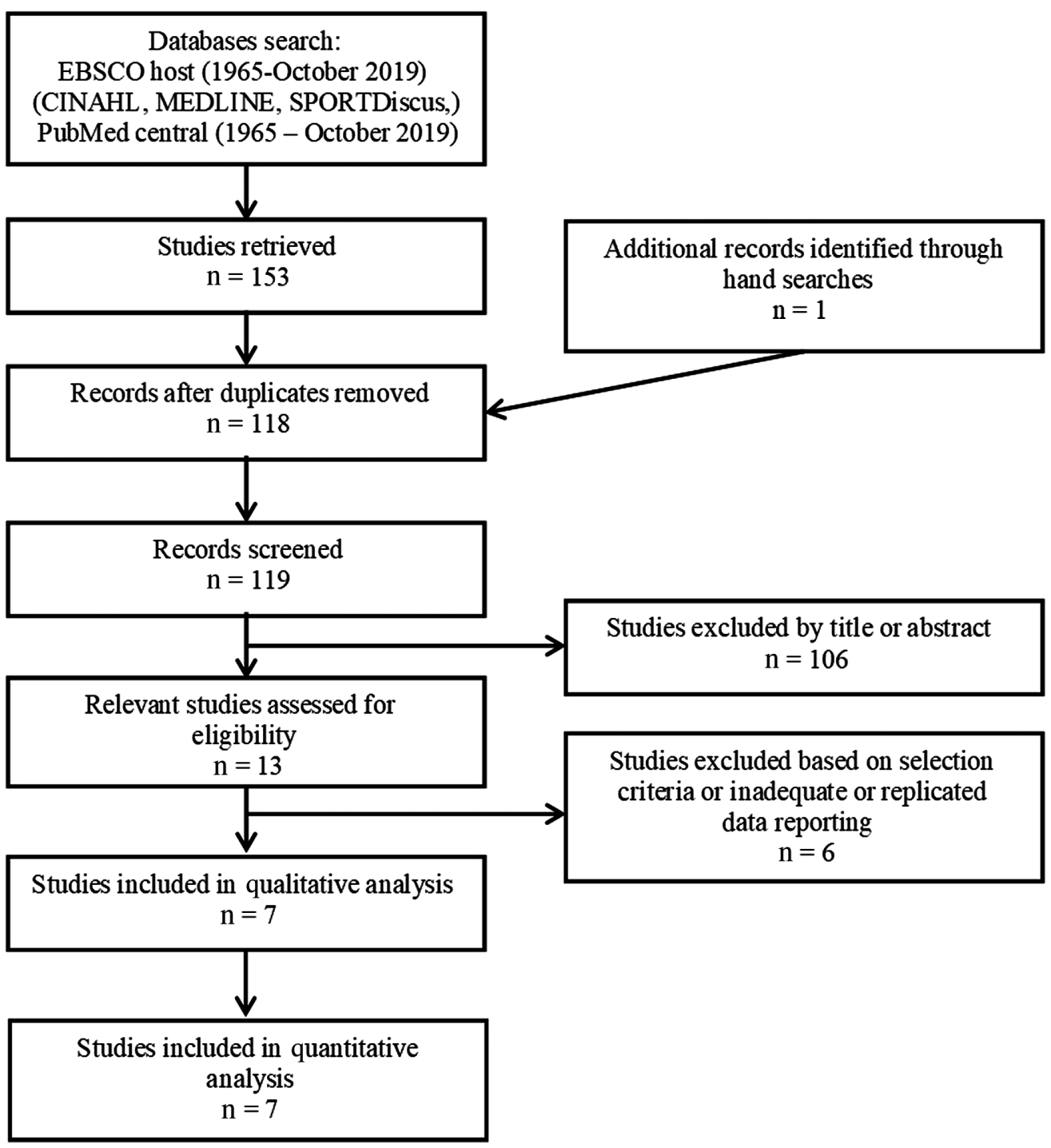

Figure 1 - Flow chart of literature review.

(95\% CI, -0.120 to 0.527$)$. There were no significant removals $(P>.099)$ indicating that no single participant group meaningfully influenced the summary effect. The 1-study-removed analysis for TTS demonstrated that the overall ES remained weak and ranged from 0.121 to 0.204 (95\% CI, -0.174 to 0.582 ) There were no significant removals $(P>.086)$ indicating that no single participant group meaningfully influenced the summary effect.

Changing the quality criterion for determining high- or lowquality studies by $\pm 10 \%$ would change recommendations based on quality evidence. An increase by $10 \%$ would cause a change from 5 high-quality studies to 0 high-quality studies. A decrease in the quality criterion by $10 \%$ would change the number of high-quality studies from 5 to 7. ${ }^{15,17-22}$ This analysis implies that the findings of this systemic review are based on articles at the lower end of highquality evidence.

\section{Level of Evidence}

The results of this review indicate that there is grade B evidence to support nonsignificant weak effect of ankle braces on dynamic balance demonstrated through either SEBT/YBT or TTS in participants with or without CAI. This recommendation for the SEBT/YBT is based on the finding from 7 level 2 studies. The recommendation for TTS is based on finding from those 7 level 2 studies. ${ }^{15,17-22}$

\section{Discussion}

The purpose of this systematic review was to summarize the literature investigating the effect of ankle braces on dynamic postural control in participants with and without CAI. The results demonstrate that there is grade $\mathrm{B}$ evidence of a nonsignificant weak overall effect on SEBT/YBT with the application of ankle braces. However, there is grade $\mathrm{B}$ evidence that a strong dynamic balance improvement occurs during SEBT/YBT tasks with the application of ankle braces in those with CAI. Some caution should be taken with this finding, however, as it was derived from a single research laboratory. There was a weak negative effect within the healthy population. The results of the subanalysis were associated with $95 \%$ CIs that did not cross 0 . Finally, there was grade B evidence of nonsignificant weak dynamic balance improvement during TTS 


\begin{tabular}{|c|c|c|c|c|}
\hline Author & $\begin{array}{l}\text { Measurement } \\
\text { technique }\end{array}$ & Brace information & Participants & Key results \\
\hline $\begin{array}{l}\text { Hadadi } \\
\text { et } \mathrm{al}^{17}\end{array}$ & $\begin{array}{l}\text { SEBT }(\mathrm{cm}) \text { A, } \\
\text { PM, PL }\end{array}$ & $\begin{array}{l}\text { Soft (Arizona Ankle Orthosis), semi- } \\
\text { ridged (Active Ankle Brace) }\end{array}$ & $\begin{array}{l}16 \mathrm{FAI} \\
10 \mathrm{M} \text { and } 6 \mathrm{~F} \\
22.9(2.2) \mathrm{y} \\
169.3 \\
(8.6) \mathrm{cm} \\
61.8(10.1) \mathrm{kg} \\
16 \text { healthy } \\
10 \mathrm{M}, 6 \mathrm{~F} \\
22.2(2.4) \mathrm{y} \\
170.3 \\
(8.4) \mathrm{cm} \\
60.2(9.3) \mathrm{kg}\end{array}$ & $\begin{array}{l}\text { No difference with ankle brace in healthy people. No } \\
\text { brace, semiridged, and soft ankle braces each increased in } \\
\text { reach distance in FAI participants }\end{array}$ \\
\hline $\begin{array}{l}\text { Hardy } \\
\text { et } \mathrm{al}^{15}\end{array}$ & $\begin{array}{l}\text { SEBT }(\mathrm{cm}) \text { A, } \\
\text { AM, AL, P, PM, } \\
\text { PL, L, M }\end{array}$ & $\begin{array}{l}\text { Semiridged (Active Ankle Brace) and } \\
\text { lace up (Ankle Stabilizer Orthosis) }\end{array}$ & $\begin{array}{l}36 \text { healthy } \\
18 \mathrm{M} \text { and } 18 \mathrm{~F} \\
23.6(2.7) \mathrm{y} \\
173.8 \\
(9.3) \mathrm{cm} \\
74.4(12.7) \mathrm{kg} \\
91.9(5.1) \mathrm{cm}\end{array}$ & $\begin{array}{l}\text { No differences in the reach distances for either brace } \\
\text { condition compared with the nonbraced healthy } \\
\text { participants }\end{array}$ \\
\hline $\begin{array}{l}\text { Willeford } \\
\text { et } \mathrm{al}^{18}\end{array}$ & $\begin{array}{l}\text { YBT }(\mathrm{cm}) \\
\text { A, PM, PL }\end{array}$ & $\begin{array}{l}\text { Lace-up Brace (McDavid } 195 \mathrm{~T} \\
\text { Ultralight) }\end{array}$ & $\begin{array}{l}29 \text { healthy } \\
29 \mathrm{M} \\
19.2(1.1) \mathrm{y} \\
187.5 \\
(20.5) \mathrm{cm} \\
106.4 \\
(20.5) \mathrm{kg}\end{array}$ & $\begin{array}{l}\text { No significant difference with brace before and after } \\
\text { football practice }\end{array}$ \\
\hline $\begin{array}{l}\text { Hadadi } \\
\text { and } \\
\text { Abbasi }^{19}\end{array}$ & $\begin{array}{l}\text { SEBT }(\mathrm{cm}) \text { AM, } \\
\text { PM, M }\end{array}$ & $\begin{array}{l}\text { Combined mechanism ankle support, } \\
\text { custom foot orthosis, and soft ankle } \\
\text { support }\end{array}$ & $\begin{array}{l}22 \mathrm{CAI} \\
10 \mathrm{M} \text { and } 12 \mathrm{~F} \\
22.7(2.6) \mathrm{y} \\
171.8 \\
(8.9) \mathrm{cm} \\
68.9(17.3) \mathrm{kg} \\
22 \text { healthy } \\
10 \mathrm{M} \text { and } 12 \mathrm{~F} \\
23.1(2.9) \mathrm{y} \\
172.1 \\
(8.6) \mathrm{cm} \\
68.2(10.9) \mathrm{kg}\end{array}$ & $\begin{array}{l}\text { Statistically significant differences were found for the } \\
\text { main effects of the groups in all COP parameters and reach } \\
\text { distances in M, AM, and PM directions. The main effect of } \\
\text { the orthotics for all evaluated parameters, except reach } \\
\text { distance in the PM direction, was statistically different. All } \\
\text { COP parameters were significantly lower with the CMAS } \\
\text { compared with other orthotic conditions in CAI patients. } \\
\text { Also, the higher reach distances with the CMAS were } \\
\text { obtained in the AM and M directions of the SEBT }\end{array}$ \\
\hline $\begin{array}{l}\text { Wikstrom } \\
\text { et } \mathrm{al}^{20}\end{array}$ & $\begin{array}{l}\text { TTS: Dynamic } \\
\text { Postural Stability } \\
\text { Index } \\
\text { M, A, V }\end{array}$ & $\begin{array}{l}\text { Lace-up (Mueller lace-up ankle brace) } \\
\text { and semiridged (McDavid Ultra Ankle } \\
\text { Brace) }\end{array}$ & $\begin{array}{l}28 \mathrm{CAI} \\
13 \mathrm{M} \\
21.5(1.2) \mathrm{y} \\
181.5 \\
(10.5) \mathrm{cm} \\
77.6(17.2) \mathrm{kg} \\
15 \mathrm{~W} \\
20.5(1.1) \mathrm{y} \\
169.4 \\
(8.2) \mathrm{cm} \\
67.9(8.8) \mathrm{kg}\end{array}$ & $\begin{array}{l}\text { Only vertical stability as a component of the DPSI was } \\
\text { improved with wearing ankle braces }\end{array}$ \\
\hline $\begin{array}{l}\text { Gribble } \\
\text { et } \mathrm{al}^{21}\end{array}$ & $\begin{array}{l}\text { TTS: resultant } \\
\text { vector (force) AP, } \\
\text { ML }\end{array}$ & Lace-up brace (Swede-O Universal) & $\begin{array}{l}\text { 15 CAI } \\
7 \mathrm{M} \text { and } 8 \mathrm{~F} \\
18.9(1.2) \mathrm{y} \\
170.8 \\
(10.2) \mathrm{cm} \\
66.9(6.9) \mathrm{kg}\end{array}$ & $\begin{array}{l}\text { Participants with CAI did not demonstrate significant } \\
\text { differences in TTS between brace and nonbraced } \\
\text { conditions }\end{array}$ \\
\hline $\begin{array}{l}\text { Shaw } \\
\text { et } \mathrm{al}^{22}\end{array}$ & $\begin{array}{l}\text { TTS: resultant } \\
\text { vector (force) AP, } \\
\text { ML }\end{array}$ & $\begin{array}{l}\text { Lace-up (Swede-O Universal lace-up } \\
\text { ankle brace) and semiridged (Active } \\
\text { Ankle Brace) }\end{array}$ & $\begin{array}{l}10 \text { healthy } \\
10 \mathrm{~F} \\
19.5(1.27) \mathrm{y} \\
179.07 \\
(7.6) \mathrm{cm} \\
69.86 \\
(5.42) \mathrm{kg}\end{array}$ & $\begin{array}{l}\text { Lace-up brace provides quicker TTS in the anterior- } \\
\text { posterior direction }\end{array}$ \\
\hline
\end{tabular}

Abbreviations: A, anterior; AL, anterior lateral; AM, anterior-medial; CMAS, combined mechanism ankle support; COP, center of pressure; DPSI, dynamic postural stability index; F, female; FAI, functional ankle insatiability; L, lateral; M, male; M, medial; P, posterior; PL, posterolateral; PM, posteromedial; SEBT, Star Excursion Balance Test; TTS, time to stabilization; V, vertical; Y, years of age; YBT, Y-Balance Test. 
Table 3 PEDro Individual Items and Quality Index Scores for the Included Articles

\begin{tabular}{|c|c|c|c|c|c|c|c|}
\hline Questions & $\begin{array}{l}\text { Hardy } \\
\text { et al }\end{array}$ & $\begin{array}{l}\text { Hadadi } \\
\text { et al }{ }^{17}\end{array}$ & $\begin{array}{l}\text { Willeford } \\
\text { et } \text { al }^{18}\end{array}$ & $\begin{array}{l}\text { Hadadi and } \\
\text { Abbasi }^{19}\end{array}$ & $\begin{array}{l}\text { Wikstrom } \\
\text { et } \mathrm{al}^{20}\end{array}$ & $\begin{array}{l}\text { Gribble } \\
\text { et al }{ }^{21}\end{array}$ & $\begin{array}{l}\text { Shaw } \\
\text { et } a^{22}\end{array}$ \\
\hline 1. Random allocation & Yes & Yes & Yes & No & Yes & No & No \\
\hline 2. Allocation concealed & Unknown & Unknown & Unknown & Unknown & Unknown & Unknown & Unknown \\
\hline 3. Similar at baseline & Yes & Yes & Yes & Yes & Yes & Yes & Yes \\
\hline 4. Blinding of all subjects & No & No & No & No & No & No & No \\
\hline 5. Blinding of all therapists & Unknown & Unknown & Unknown & Unknown & Unknown & Unknown & Unknown \\
\hline 6. Blinding of all assessors & Unknown & Unknown & Unknown & Unknown & Unknown & Unknown & Unknown \\
\hline 7. More than $85 \%$ of follow-up & Yes & Yes & Yes & Yes & Yes & Yes & Yes \\
\hline 8. Intention to treat & Yes & Yes & Yes & Yes & Yes & Yes & Yes \\
\hline $\begin{array}{l}\text { 9. Between-groups statistical } \\
\text { comparison }\end{array}$ & Yes & Yes & Yes & Yes & Yes & Yes & Yes \\
\hline $\begin{array}{l}\text { 10. Point measures and } \\
\text { variability }\end{array}$ & Yes & Yes & Yes & Yes & Yes & Yes & Yes \\
\hline 11. Eligibility criteria indicated & Yes & Yes & Yes & Yes & Yes & Yes & Yes \\
\hline Percentage of yes, $\%$ & $6 / 10=60.00$ & $6 / 10=60.00$ & $6 / 10=60.00$ & $6 / 10=60.00$ & $6 / 10=60.00$ & $5 / 10=50.00$ & $5 / 10=50.00$ \\
\hline Level of evidence & 2 & 2 & 2 & 2 & 2 & 2 & 2 \\
\hline
\end{tabular}

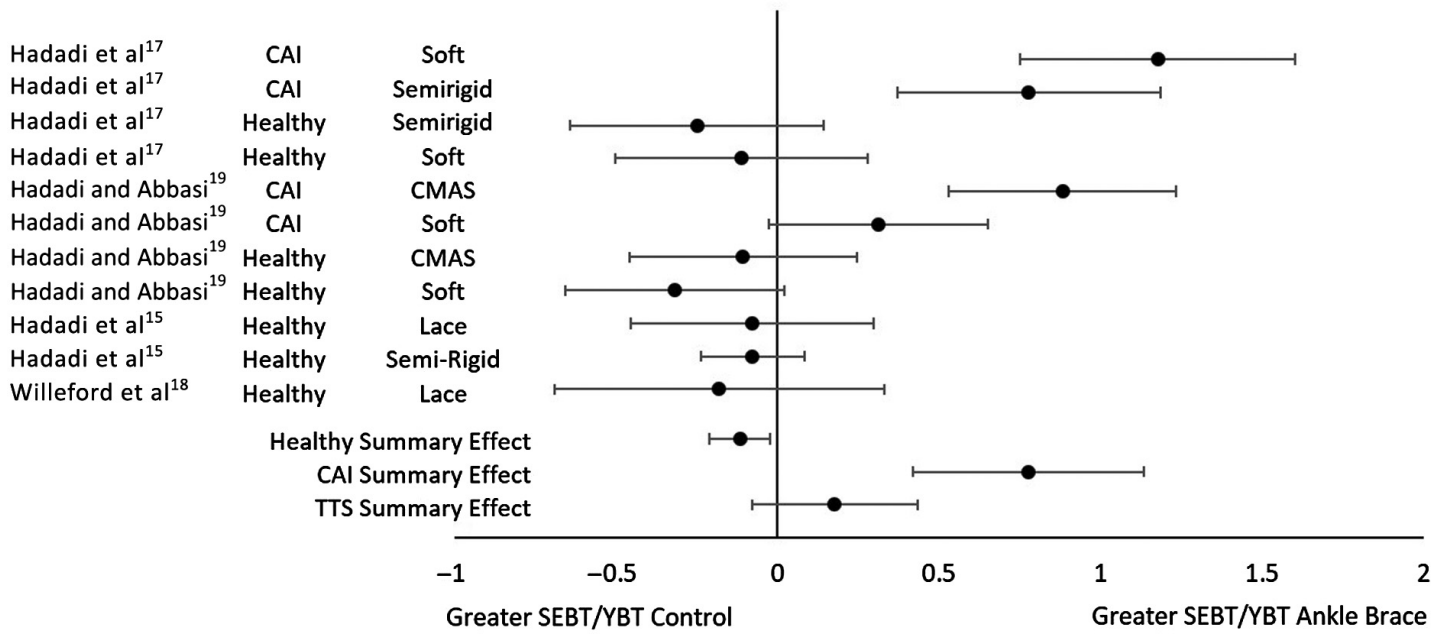

Figure 2 - Forest plot of Hedges $g$ effects sizes and 95\% confidence intervals for SEBT/YBT. CAI indicates chronic ankle instability; SEBT, Star Excursion Balance Test; YBT, Y-Balance Test.

tasks. The overall analyses were associated with $95 \%$ CIs that crossed 0 .

Findings from this systematic review indicate that there is a weak overall effect of ankle braces on SEBT/YBT. However, subanalysis demonstrated a negative weak ES in the healthy participants and a strong effect in those with CAI. The CAI is a condition associated with sensorimotor alterations that contribute to dynamic balance impairments. ${ }^{26}$ Perhaps these alterations produce conditions where ankle braces can make an impact unlike in healthy individuals. In addition, there is literature to suggest ankle braces enhance dynamic balance during states of fatigue. ${ }^{22}$ States of fatigue are similar to CAI in that both conditions cause sensorimotor alterations. ${ }^{22,26}$ In combination, these findings may indicate that ankle braces only effect dynamic balance in states of impairment. Furthermore, fatigue is common in the latter half of competitions, which is typically when ankle sprains are most likely to occur. ${ }^{27}$ This may indicate that the greatest effect of the ankle braces on injury risk, through augmenting dynamic balance, is during periods when ankle sprains are most common. Further research is needed to explore effect of ankle braces on dynamic balance during various impairment conditions.

Overall, summary SEBT/YBT and TTS data demonstrated a weak effect of ankle braces on dynamic balance. However, there were variations within the included studies regarding ankle brace composition. Ankle braces used in articles for this review include semirigid ankle braces, lace-up ankle braces, soft ankle braces, and combined mechanism ankle braces. Regardless of the ankle brace used, effect on dynamic balance seemed to be consistent. Within the SEBT/YBT, ESs ranged from -0.317 to -.077 for healthy and 0.313 to 1.177 for CAI participants. TTS data had similar results 


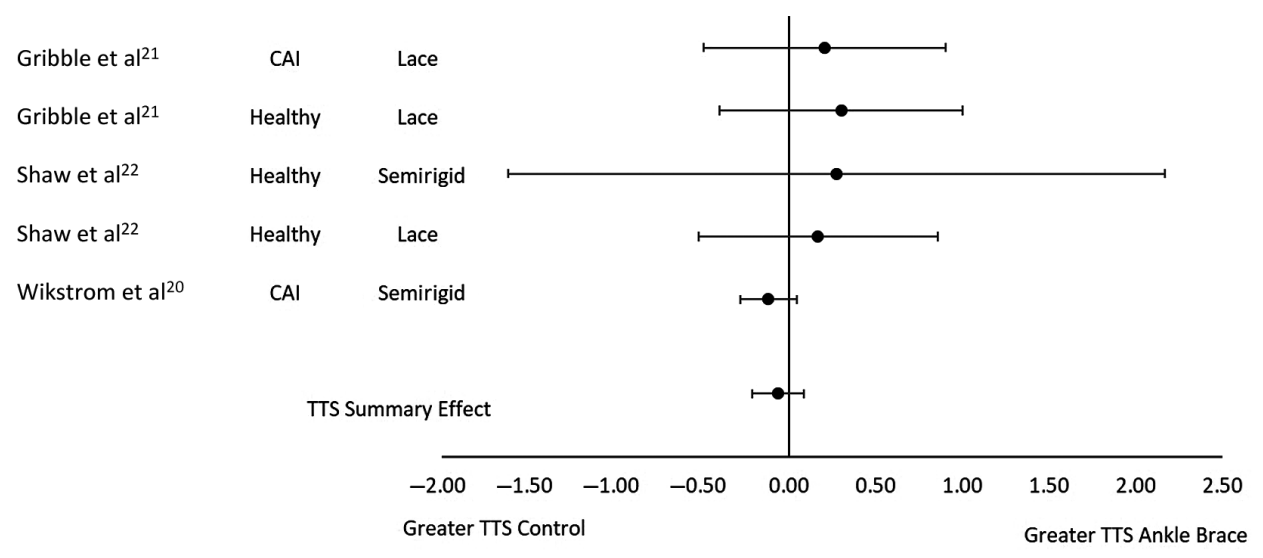

Figure 3 - Forest plot of Hedges $g$ effects sizes and 95\% confidence intervals for TTS. CAI indicates chronic ankle instability; TTS, Time to Stabilization.

with ESs that ranged from -0.118 to 0.303 . This indicates that at this time there is not 1 ankle brace style that impacts dynamic balance more than another. Finally, we identified greater trends toward improvement of the SEBT/YBT compared with TTS. Based on this systematic review, we are unsure as to why differences were seen between the 2 balance tasks with regards to ankle braces. However, differences may be due to variations in physical demand between the 2 tasks such as muscle recruitment, speed, and coordination. For example, TTS is inherently a more demanding and expedient task that does not give the participant ample time to adjust while completing the task to enhance their score. The SEBT/ YBT on the other hand is a slower and more deliberate dynamic balance task where there may be more opportunities to take advantage of enhanced feedback or ankle restrictions during the task. Further research is needed to determine differences between tasks and on the effect of different ankle braces.

\section{Practical Implications}

Ankle braces have been used as effective tools for both the treatment and the primary and secondary prevention of ankle sprains. ${ }^{11,28}$ Proposed mechanisms suggest that ankle braces may reduce injury incidence through mechanical, sensory, and balance changes. The results of this review demonstrate that individuals with CAI have improved dynamic balance while using a variety of ankle braces. Although ankle braces had the greatest effect on dynamic balance in those with diminished ankle function such as with CAI, they should potentially be used in anticipation of fatigued states that cause similar impairments to dynamic balance. However, more research is needed to elucidate the mechanism of how this benefit occurs.

\section{Limitations of Review}

There were several different types of ankle braces and a lack of ankle brace consistency within the included articles. This makes it difficult to assess the effect of individual braces and provide recommendations as to the optimal brace to effect dynamic balance. Future research is needed that includes consistent braces to allow for comparison. In addition, only healthy or CAI participants were examined under dynamic balance conditions. This makes it difficult to assess the effect of ankle braces in a variety of other lower-extremity impairments that could impact dynamic balance and injury risk. Research is needed that includes a variety of lowerextremity impairments in order to make recommendations for ankle braces in different situations. Furthermore, the investigation of ankle braces effects on those with CAI was limited to 2 studies ${ }^{17,19}$ completed by one research group 5 years apart. Due to this, caution should be taken when evaluating the CAI finding as it has not been reproduced by other groups. The effect of ankle braces on dynamic balance is not directly related to injury prevention. Researchers and clinicians are still unsure of the mechanism for ankle braces effect on injury prevention. Prospective research designs are needed to evaluate ankle braces effect on dynamic balance changes and its relationship to injury risk reduction.

\section{Conclusion}

The results of this systematic review demonstrate that there is grade B evidence to support weak to no overall effect of prophylactic ankle braces on SEBT/YBT and TTS. However, subanalysis shows that there is grade $\mathrm{B}$ evidence from one research laboratory to support a strong effect of prophylactic ankle braces on SEBT/YBT in those with CAI. These results infer that ankle braces are a contributing factor to changes in dynamic balance when measured through the SEBT/YBT but not TTS among those with CAI. Therefore, dynamic balance may be a contributing factor to ankle sprain reduction in those with CAI with ankle brace use. The direction of future research should include studies with consistent ankle brace type, various pathologic populations, and the examination of dynamic balance changes due to the effect of ankle braces on injury risk.

\section{Acknowledgment}

There is no financial support to disclose.

\section{References}

1. Anandacoomarasamy A, Barnsley L. Long term outcomes of inversion ankle injuries. Br J Sports Med. 2005;39(3):e14. PubMed ID: 15728682 doi:10.1136/bjsm.2004.011676 
2. Yeung MS, Chan KM, So CH, Yuan WY. An epidemiological survey on ankle sprain. Br J Sports Med. 1994;28(2):112-116. PubMed ID: 7921910 doi:10.1136/bjsm.28.2.112

3. Doherty C, Bleakley C, Hertel J, Caulfield B, Ryan J, Delahunt E. Recovery from a first-time lateral ankle sprain and the predictors of chronic ankle instability: a prospective cohort analysis. Am J Sport Med. 2016;44(4):995-1003. doi:10.1177/0363546516628870

4. Houston MN, Van Lunen BL, Hoch MC. Health-related quality of life in individuals with chronic ankle instability. J Athl Train. 2014;49(6): 758-763. PubMed ID: 25299444 doi:10.4085/1062-6050-49.3.54

5. Hubbard-Turner T, Turner MJ. Physical activity levels in college students with chronic ankle instability. J Athl Train. 2015;50(7):742747. PubMed ID: 25898110 doi:10.4085/1062-6050-50.3.05

6. Anderson DD, Chubinskaya S, Guilak F, et al. Post-traumatic osteoarthritis: improved understanding and opportunities for early intervention. J Orthop Res. 2011;29(6):802-809. PubMed ID: 21520254 doi:10.1002/jor.21359

7. Waterman B, Owens B, Davey S, Zacchilli M, Belmont P, Jr. The epidemiology of ankle sprains in the United States. J Bone Joint Surg Am. 2010;92(13):2279-2284. PubMed ID: 20926721 doi:10.2106/ JBJS.I.01537

8. McGuine TA, Brooks A, Hetzel S. The effect of lace-up ankle braces on injury rates in high school basketball players. Am J Sports Med. 2011;39(9):1840-1848. PubMed ID: 21795671 doi:10.1177/ 0363546511406242

9. Bellows R, Wong CK. The effect of bracing and balance training on ankle sprain incidence among athletes: a systematic review with metaanalysis. Int J Sports Phys Ther. 2018;13(3):379-388. PubMed ID: 30038824 doi:10.26603/ijspt20180379

10. McGuine TA, Hetzel S, Wilson J, Brooks A. The effect of lace-up ankle braces on injury rates in high school football players. Am J Sports Med. 2012;40(1):49-57. PubMed ID: 21926383 doi:10.1177/ 0363546511422332

11. Vuurberg G, Hoorntje A, Wink LM, et al. Diagnosis, treatment and prevention of ankle sprains: update of an evidence-based clinical guideline. Br J Sport Med. 2018;52(15):956. doi:10.1136/bjsports2017-098106

12. Cordova ML, Ingersoll CD, LeBlanc MJ. Influence of ankle support on joint range of motion before and after exercise: a meta-analysis. $J$ Ortho Sport Phys Ther. 2000;30(4):170-182. doi:10.2519/jospt.2000. 30.4.170

13. Cordova ML, Ingersoll CD, Palmieri RM. Efficacy of prophylactic ankle support: an experimental perspective. J Athl Train. 2002;37(4): 446-457. PubMed ID: 12937566

14. Maeda N, Urabe Y, Tsutsumi S, et al. Effect of semi-rigid and soft ankle braces on static and dynamic postural stability in young male adults. J Sport Sci Med. 2016;15(2):352-357.

15. Hardy L, Huxel K, Brucker J, Nesser T. Prophylactic ankle braces and star excursion balance measures in healthy volunteers. $J$ Athl Train. 2008;43(4):347-351. PubMed ID: 18668181 doi:10.4085/ 1062-6050-43.4.347

16. Gribble PA, Hertel J, Plisky P. Using the Star Excursion Balance Test to assess dynamic postural-control deficits and outcomes in lower extremity injury: a literature and systematic review. J Athl Train. 2012;47(3):339-357. PubMed ID: 22892416 doi:10.4085/10626050-47.3.08

17. Hadadi M, Mousavi ME, Fardipour S, Vameghi R, Mazaheri M. Effect of soft and semirigid ankle orthoses on Star Excursion Balance Test performance in patients with functional ankle instability. $J$ Sci Med Sport. 2014;17(4):430-433. PubMed ID: 23810776 doi:10. 1016/j.jsams.2013.05.017

18. Willeford K, Stanek JM, McLoda TA. Collegiate football players' ankle range of motion and dynamic balance in braced and selfadherent-taped conditions. J Athl Train. 2018;53(1):66-71. PubMed ID: 29314872 doi:10.4085/1062-6050-486-16

19. Hadadi M, Abbasi F. Comparison of the effect of the combined mechanism ankle support on static and dynamic postural control of chronic ankle instability patients. Foot Ankle Int. 2019;40(6):702709. PubMed ID: 30808178 doi:10.1177/1071100719833993

20. Wikstrom EA, Arrigenna MA, Tillman MD, Borsa PA. Dynamic postural stability in subjects with braced, functionally unstable ankles. J Athl Train. 2006;41(3):245-250. PubMed ID: 17043691

21. Gribble PA, Taylor BL, Shinohara J. Bracing does not improve dynamic stability in chronic ankle instability subjects. Phys Ther Sport. 2010;11(1):3-7. PubMed ID: 20129116 doi:10.1016/j.ptsp. 2009.11.003.

22. Shaw MY, Gribble PA, Frye JL. Ankle bracing, fatigue, and time to stabilization in collegiate volleyball athletes. J Athl Train. 2008; 43(2):164-171. PubMed ID: 18345341 doi:10.4085/1062-6050-43. 2.164

23. Liberati A, Altman DG, Tetzlaff J, et al. The PRISMA statement for reporting systematic reviews and meta-analyses of studies that evaluate health care interventions: explanation and elaboration. PLoS Med. 2009;6(7):e1000100. PubMed ID: 19621070 doi:10.1371/ journal.pmed.1000100

24. de Morton NA. The PEDro scale is a valid measure of the methodological quality of clinical trials: a demographic study. Aust J Physiother. 2009;55(2):129-133. PubMed ID: 19463084 doi:10.1016/ S0004-9514(09)70043-1

25. Ebell MH, Siwek J, Weiss BD, et al. Strength of recommendation taxonomy (SORT): a patient-centered approach to grading evidence in the medical literature. J Am Board Fam Pract. 2004;17(1):59-67. PubMed ID: 15014055 doi:10.3122/jabfm.17.1.59

26. Hertel J, Corbett RO. An updated model of chronic ankle instability. $J$ Athl Train. 2019;54(6):572-588. PubMed ID: 31162943 doi:10. 4085/1062-6050-344-18

27. de Noronha M, Lay EK, McPhee MR, Mnatzaganian G, Nunes GS. Ankle sprain has higher occurrence during the latter parts of matches: systematic review with meta-analysis. J Sport Rehabil. 2019;28(4):373-380. PubMed ID: 29809104 doi:10.1123/jsr.20170279

28. Barelds I, van den Broek AG, Huisstede BMA. Ankle bracing is effective for primary and secondary prevention of acute ankle injuries in athletes: a systematic review and meta-analyses. Sports Med. 2018;48(12):2775-2784. PubMed ID: 30298478 doi:10.1007/s40279018-0993-2 